\title{
Fibroepithelial Polyp of Vagina - A Rare Case Report
}

\author{
Sujata Kumbhar ${ }^{1 *}$, Digvijay Patil ${ }^{2}$, Shoaib Khoja ${ }^{3}$, Garima Agarawal ${ }^{3}$, Divya Brahmbhatt ${ }^{3}$, Vaidehi Nagar ${ }^{3}$
}

${ }_{1}^{1}$ Professor, Department of Pathology, Krishna Institute of Medical Sciences, Deemed to be University, Karad, India
${ }^{2}$ Department of Obstetrics and Gynaecology, Krishna Institute of Medical Sciences, Deemed to be University, Karad, India
${ }^{3}$ Tutor, Department of Pathology, Krishna Institute of Medical Sciences, Deemed to be University, Karad, India

DOI: $10.36347 /$ sjmcr.2020.v08i11.012

| Received: 12.10.2020 | Accepted: 25.10.2020 | Published: 20.11.2020

*Corresponding author: Dr. Sujata Kumbhar

Abstract

Polypoid lesions or grape like masses of vagina are always worrisome and uncommon. In infants and young girls, such lesions are suspicious for sarcoma botryoides. In adults, benign vaginal polyps with bizarre stromal cells may occur, leading to a misdiagnosis of sarcoma. Fibroepithelial polyps of the vagina (FEPV) have attracted special interest during the past decades because of the presence of atypical cells and abnormal mitoses in some of them 2'. Fibroepithelial polyps of the vagina (FEPV) are mucosal polypoid lesions with a connective tissue core covered by a benign squamous epithelium. They are thought to be rare. Here we present an unusual case of 42 years old female patient with complaint of pain in lower abdomen since 6 months diagnosed with fibroepithelial polyp of the vagina (FEPV).

Keywords: Polypoid lesions, botryoides, epithelium, fibroepithelial.

Copyright $\left({ }_{0} 2020\right.$ The Author(s): This is an open-access article distributed under the terms of the Creative Commons Attribution 4.0 International License (CC BY-NC 4.0) which permits unrestricted use, distribution, and reproduction in any medium for non-commercial use provided the original author and source are credited.

\section{INTRODUCTION}

Polypoid lesions or grape like masses of vagina are always worrisome and uncommon. In infants and young girls, such lesions are suspicious for sarcoma botryoides. In adults, benign vaginal polyps with bizarre stromal cells may occur, leading to a misdiagnosis of sarcoma. Polyp that may be similar both grossly and microscopically, but that behavein a benign fashion and both of which are rare.

Fibroepithelial polyps are benign lesions that can affect the lower female genital tract. FEPV are mucosal polypoid lesions with a connective tissue core covered by a benign squamous epithelium. They are thought to be rare as few cases are reported in literature. The lesions can vary in size and number and appear to be hormonally related and have been reported more often in pregnant women. Although benign, it can be confused with sarcoma botryoides, rhabdomyosarcoma and mixed mesodermal tumor because of its bizarre histology. FEPV should be considered in the differential for vaginal neoplasm.

\section{Case Report}

A 42 years old female patient presented with complaint of pain in lower abdomen since 6 months. There is no per vaginal discharge. Colposcopy shows no abnormality. However there is $1 \mathrm{x} 1 \mathrm{~cm}$ hard indurated mass on posterior vaginal wall.

\section{GROSS}

Received multiple (Two), irregular, grey white, soft tissue bit. One measures 0.4 × 0.4 × 0.1 and other tissue bit measures $0.2 \times 0.2 \times 0.1 \mathrm{~cm}$. They were called as skin tags, were pedunculated or sessile. They had either smooth surfaces. The cut surface was uniform and soft grey or pearly white.

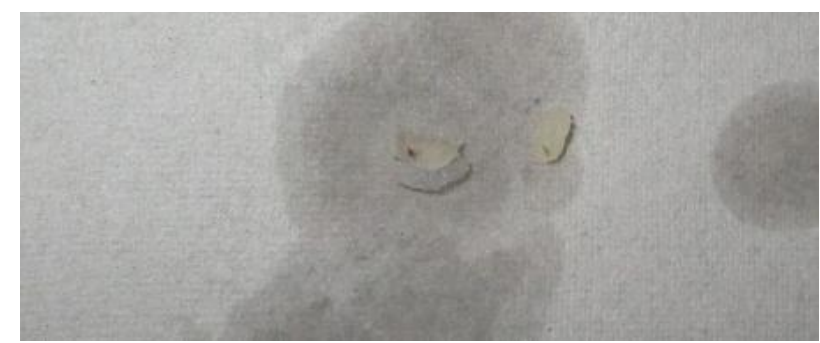

Fig-1: Gross: Two irregular, grey white, soft tissue bits

\section{MICROSCOPIC FINDINGS}

Microscopic examination on low power revealed polypoid structures covered with benign squamous epithelium. A focal area (tip) of the polyp showed focal ulceration with numerous dense acute and chronic inflammatory cells. There were also irregular dilated blood vessels in the fibrous connective tissue. At 
the base and midportion of the polyp the stroma was composed of loose fibrous connective tissue without any hypercellularity. On high power there were, within the stroma, plump cells resembling fibroblast, with delicate branching cytoplasm process and dark vesicular nuclei. No large atypical stromal cells were identified (Fig $2 \& 3$ ).

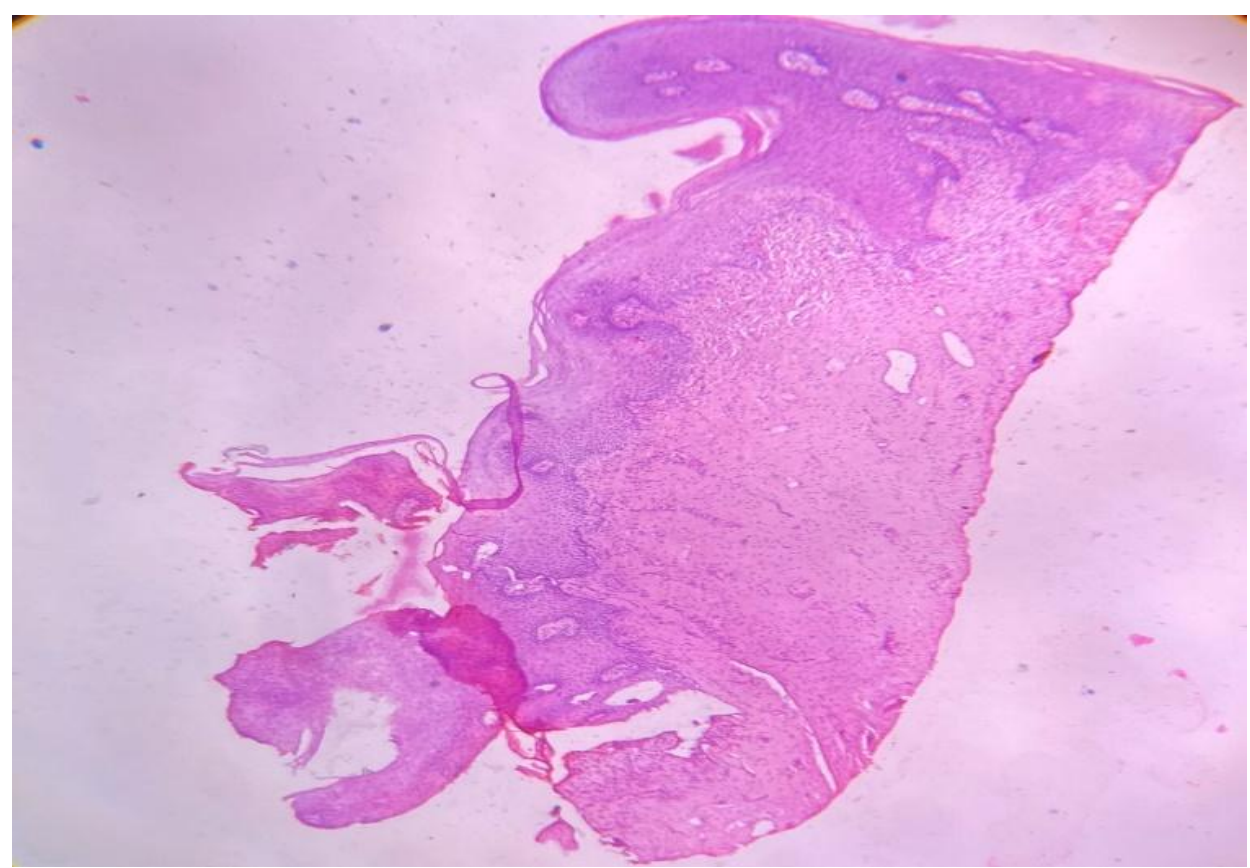

Fig-2: Polypoid structures covered with benign squamous epithelium

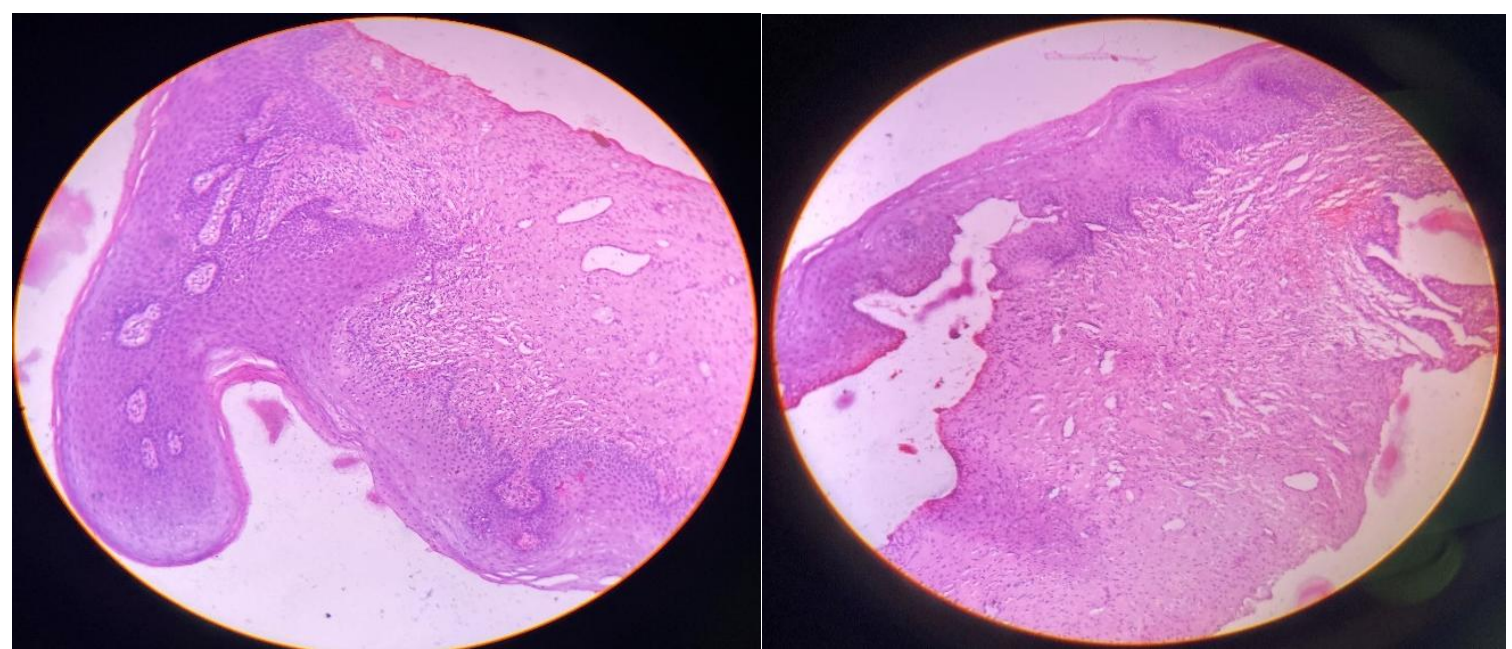

Fig-3: Focal area (tip) of the polyp showed focal ulceration with numerous dense acute and chronic inflammatory cells

\section{DISCUSSION}

Fibroepithelial polyps of the vagina are uncommon benign lesions that may have a bizarre histologic appearance. Consequently, they are of concern for their potential to be misdiagnosed as malignant tumors of the vaginal connective tissue. The patient's age is an important indicator of the benign nature of these lesions, because sarcoma botryoides occurs almost exclusively in girls under the age of 8 years. The etiology of these polyps is unclear. Elliott and Elliott [3] described a 0.5 to $5.0 \mathrm{~mm}$ subepithelial myxoid stromal zone extending from vulva to endocervix in mature women. Approximately $25 \%$ of healthy women demonstrated anisonucleosis in this zone with bizarre nuclear features similar to those seen in fibroepithelial polyps. Elliott et al., [4] comment that the "bizarre overgrowth of the subepithelial mesenchyme may be an excessive response of some Mullerian tissue to growth-provoking hormones.

Burt et al., [5] reported that 3 of 5 patients had a history of hormone replacement, suggesting a possible contribution of hormonal stimulation to the development of stromal hypertrophy and polyp formation.

Thus, it may be that the hormone-rich environment existing in pregnant women may stimulate 
excessive growth of the stromal zone described by Elliott and Elliott.

"In summary, fibroepithelial polyps are uncommon benign vaginal lesions that raise the specter of sarcoma botryoides. Although they may occur in pregnancy, the pregnancy does not appear to have an influence on the degree of stromal atypia. Spontaneous vaginal delivery is not contraindicated. Local excision is curative, and the subsequent course is benign.

\section{CONCLUSION}

FEPV are common lesions with benign mono and multinucleated fibroblastic stromal cells in which myoid differentiation is often present. It may develop as a result of granulation tissue reaction after some local injury of vaginal mucosa. Hormonal factor may play a role in modulating growth of polyp. Delayed differentiation of myofibroblastic cells may explain why granulation sometimes does not contract properly but turns into polyp.

\section{REFRENCES}

1. Burt RL, Prichard RW, Kim BS. Fibroepithelial polyp of the vagina. A report of five cases. Obstet Gynecol. 1990; 47(suppl 1):52s-4s.

2. Mitchell M, Talerman A, Scholl JS, Ogagaki T, Cibils LA. Psudosarcoma botryoides in pregnancy: Report of a case with ultrastructural observations. Obstet Gynecol. 1987; 70:522-6

3. Elliott GB, Elliott JDA: Superficial stromal reactions of lower genital tract/Arch Pathol. 1973; 95:100-101.

4. Elliott GB, Reynolds HA, Fidler HK: Pseudosarcoma botryoides of cervix and vagina in pregnancy. J Obstet GynaecolbBr Commonw. 1967; 74:728-733.

5. Burt RL, Prichard RW, Kim BS: Fibroepithelial polyps of the vagina. Obstet Gyencol. 1976; 47:52s-54s. 